\title{
Parental and early life stage environments drive establishment of bacterial and dinoflagellate communities in a common coral
}

\author{
Hannah E. Epstein ${ }^{1,2,3} \cdot$ Gergely Torda $^{1,2} \cdot$ Philip L. Munday ${ }^{1} \cdot$ Madeleine J. H. van Oppen ${ }^{2,4}$
}

Received: 26 September 2018 / Revised: 15 January 2019 / Accepted: 17 January 2019 / Published online: 31 January 2019

(c) International Society for Microbial Ecology 2019

\begin{abstract}
The establishment of coral microbial communities in early developmental stages is fundamental to coral fitness, but its drivers are largely unknown, particularly for bacteria. Using an in situ reciprocal transplant experiment, we examined the influence of parental, planulation and early recruit environments on the microbiome of brooded offspring in the coral Pocillopora damicornis. 16S rRNA and ITS2 rDNA gene metabarcoding showed that bacterial and microalgal endosymbiont communities varied according to parental and planulation environments, but not with early recruit environment. Only a small number of bacterial strains were shared between offspring and their respective parents, revealing bacterial establishment as largely environmentally driven in very early life stages. Conversely, microalgal communities of recruits were highly similar to those of their respective parents, but also contained additional low abundance strains, suggesting both vertical transmission and novel ('horizontal') acquisition. Altogether, recruits harboured more variable microbiomes compared to their parents, indicating winnowing occurs as corals mature.
\end{abstract}

\section{Introduction}

Corals are host to a diverse consortium of microbial partners, some of which are essential to the health and function of the coral holobiont (reviewed in [1]). Initial establishment of these microbial communities in each new generation of coral can occur through horizontal $[2,3]$ or vertical $[4,5]$ transmission, or a combination of both (i.e., "mixed mode transmission", [6]). In corals, the transmission of microalgal endosymbionts in the family Symbiodiniaceae

Supplementary information The online version of this article (https:// doi.org/10.1038/s41396-019-0358-3) contains supplementary material, which is available to authorized users.

Hannah E. Epstein

hannah.epstein@my.jcu.edu.au

1 ARC Centre of Excellence for Coral Reef Studies, James Cook University, Townsville, QLD 4811, Australia

2 Australian Institute of Marine Science, PMB 3, Townsville, QLD 4810, Australia

3 AIMS@JCU, James Cook University, Townsville, QLD 4811, Australia

4 School of BioSciences, University of Melbourne, Parkville, VIC 3010, Australia is often correlated with reproductive mode, where brooders exhibit vertical or mixed mode transmission and broadcast spawners exhibit horizontal transmission [7]. However, this pattern is not well defined for bacteria, as previous studies on bacterial transmission have found variability within coral reproductive modes. For instance, horizontal transmission of bacteria occurs in a number of broadcast spawning corals including Pocillopora meandrina [3] and Montastrea, Acropora and Diploria species [8], whereas other broadcast spawners, such as Mussimilia hispida [5] and Acropora gemmifera [9], and the brooding coral Porites astreoides [10] have been suggested to vertically transfer some key bacterial taxa from parents to gametes prior to spawning.

Laboratory or ex situ studies on microbial transmission mode may not reveal the complete picture due to the artificial composition of the environmental microbial community. To remove this bias, we investigated the drivers of Symbiodiniaceae and bacterial establishment in the coral Pocillopora damicornis, a cosmopolitan branching species, in the field. We conducted an in situ reciprocal transplant experiment between two adjacent reef habitat types, the reef flat and slope, where both brooding parental whole coral colonies and newly settled recruits were cross-transplanted to both habitats (for detailed methods, see Supplementary Information SI.1). From each habitat, ten adult $P$. 
damicornis (i.e., parental environment) were placed individually into settlement boxes (acrylic boxes fit with 300 $\mu \mathrm{m}$ plankton mesh on two sides and the base covered in nine $11 \times 11 \mathrm{~cm}$ settlement tiles) and reciprocally transplanted prior to planulation. Once planulae settled and metamorphosed on the settlement tiles (i.e., planulation environment), these were again reciprocally transplanted between habitats (i.e., transplant environment) and recruits were sampled after 1 week. Recruits were defined by their parental, planulation and transplant environments, referred to as experimental groups. Symbiodiniaceae and bacterial community composition were determined by Illumina sequencing of ITS2 rDNA and 16S rRNA gene amplicons (see Supplementary Information SI.2).

\section{Results and Discussion}

The establishment of bacterial communities in $P$. damicornis offspring was driven by both parental and planulation environments, with the majority of uptake occurring horizontally through chance encounter in the environment. Bacterial communities of recruits differed significantly from both parents and water samples from the reef flat and slope, and also
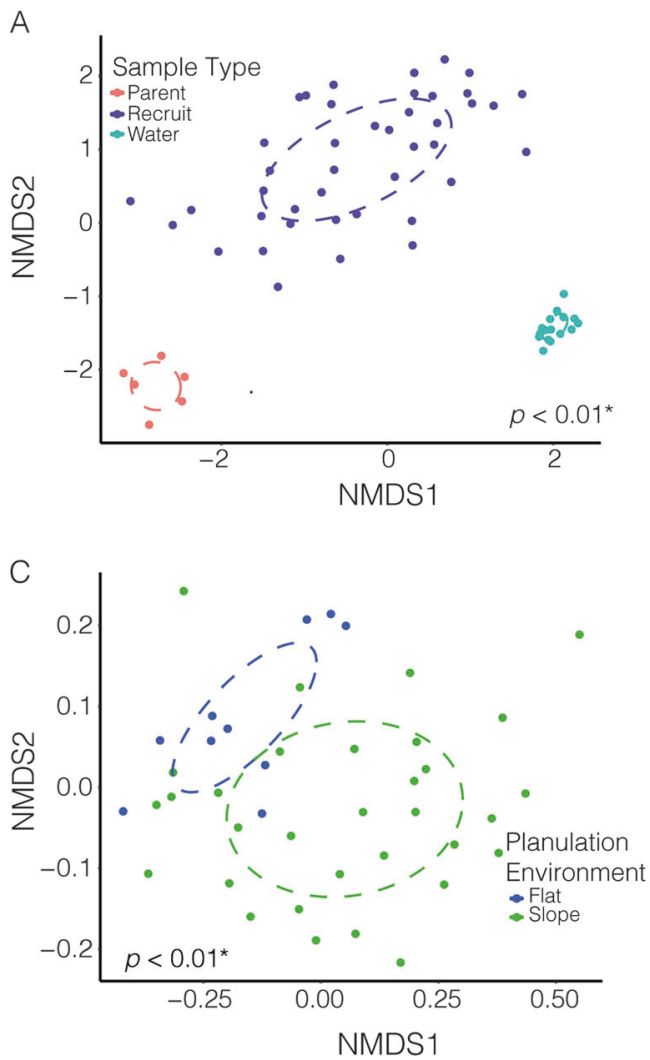

Fig. 1 Non-parametric multi-dimensional scaling (nMDS) visualisation of bacterial beta-diversity of a all samples grouped by sample type; parent, recruit or water, $\mathbf{b}$ recruit samples grouped by parental displayed much greater dispersion than the parents or water samples (Fig. 1a; Fig. S1; see Supplementary Information SI.3). Recruits significantly varied according to the parental (PERMANOVA: $d f=1, F=3.848, p=0.001$ ) and planulation environments (PERMANOVA: $d f=1, \quad F=$ 4.1384, $p=0.001$ ), but not by transplant environment (Fig. 1b-d), suggesting parental and very early life stage environments (e.g., prior to or immediately following settlement) shape the bacterial communities of young recruits. Further, each cohort of recruits and respective parent shared a small number of bacterial amplicon sequence variants (ASVs) in several genera including Endozoicomonas, Vibrio, Alteromonas and Ruegeria (Table S1). Only one ASV of Burkholderia-Paraburkholderia was shared among all parents and all recruits. While its consistent presence among all coral samples could represent potential evidence for vertical transmission, this ASV may also be acquired after planulation from the seawater; fluorescent in situ hybridisation is required for verification. Vertical transmission of Burkholderia has previously been suggested for the spawning coral, Mussimillia hispida [5]. As a possible nitrogen fixer [11, 12], it could provide otherwise limited nitrogen to the Symbiodiniaceae and assist in the survival and protection of early recruits $[13,14]$.
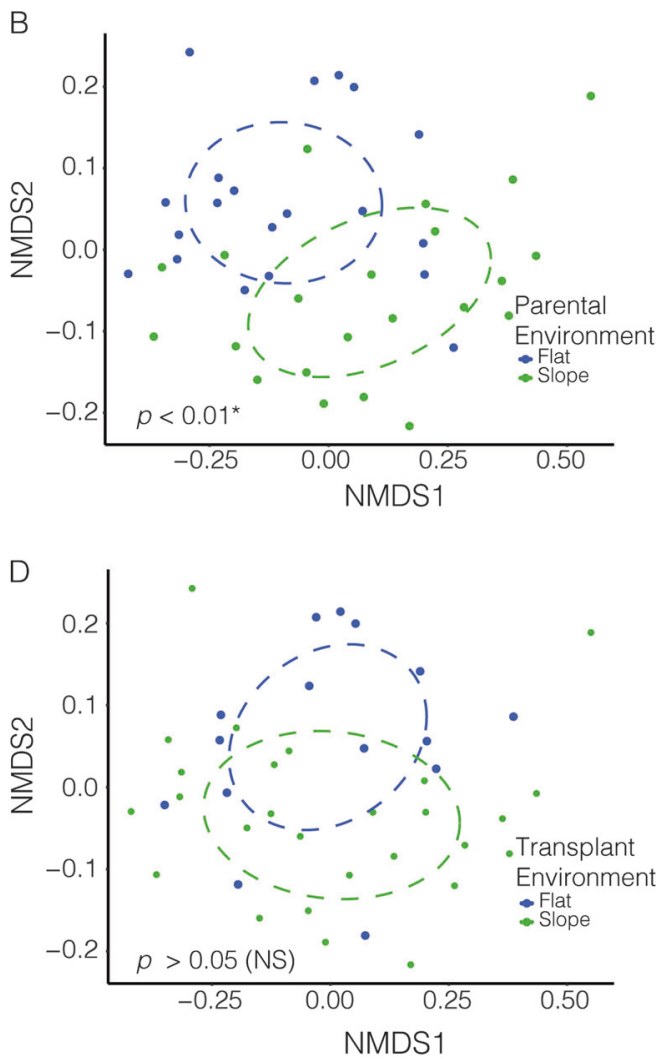

environment, $\mathbf{c}$ recruit samples grouped by planulation environment and $\mathbf{d}$ recruit samples grouped by transplant environment. $p$-values represent results from PERMANOVA 
Fig. 2 a Alpha diversity and b richness ( $p$-value represents results from ANOVA) of Symbiodiniaceae between sample types; parent, recruit and water. c Principal component analysis plot of parent and recruit samples labelled according to sample type and parental ID where appropriate, clearly showing parents (circles outlined in black) clustering with respective recruits ( $p$-value represents results from PERMANOVA). Inset graph represents dispersion by sample type ( $p$-value represents results from PERMDISP)
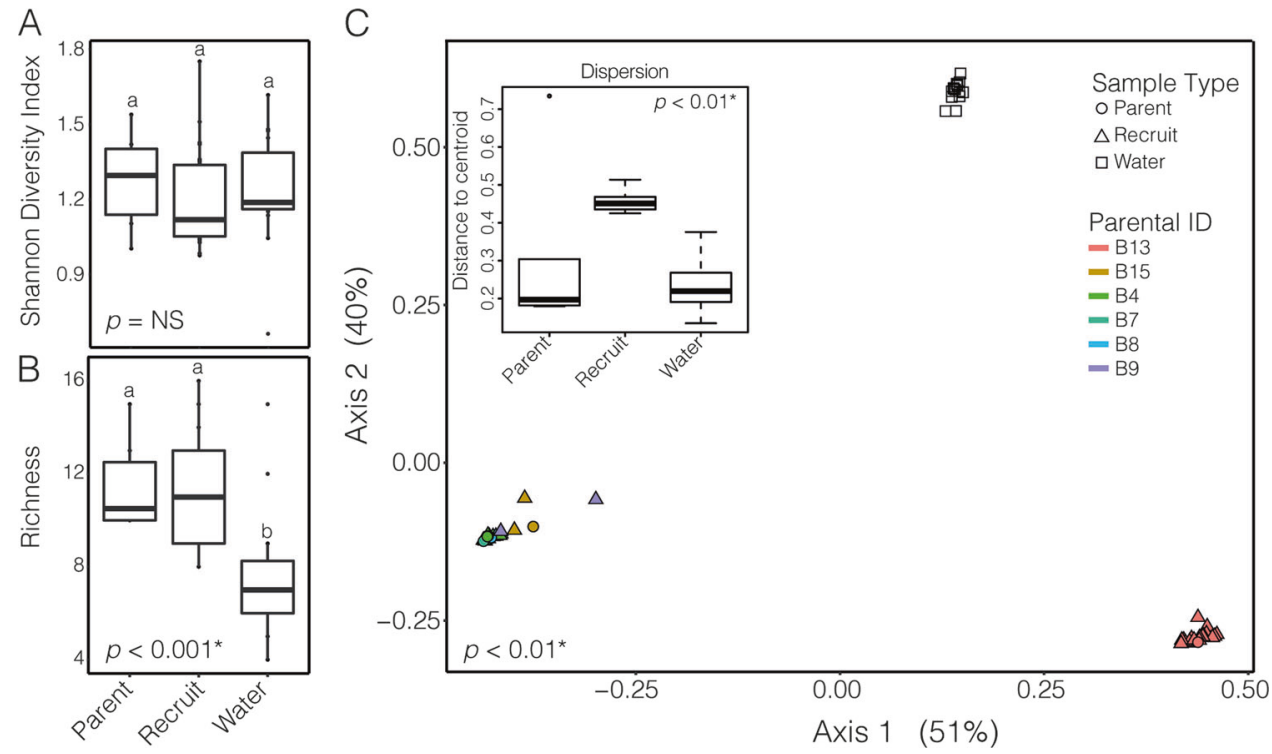

Symbiodiniaceae communities were also driven by both parental and planulation environments. Parental colonies and their respective offspring harboured similar Symbiodiniaceae communities and shared dominant strains (Fig. 2a-c). Alpha diversity remained consistent across all sample types, but richness was significantly lower in water compared to coral samples. Recruit communities correlated significantly with both the parental (PERMANOVA: $d f=1, F=135.94$, $p=0.001$ ) and the planulation environment (PERMANOVA: $d f=1, F=15.2, p=0.001)$, but not the transplant environment. The significant effect of planulation environment found here, with evidence of low abundance background strains that were present in recruits but not parents (Table S2), suggests that in addition to vertically receiving some Symbiodinaceae strains from their parents (e.g., [15]), recruits horizontally acquired some strains from their environment at this early life stage. This is consistent with recent reports on other pocilloporids (e.g, Stylophora pistillata, [16]; Seriatopora hystrix, [6]).

Recruits harboured more variable bacterial and Symbiodiniaceae communities in comparison to their parents. This confirms earlier studies showing a "winnowing" of microbial assemblages, where these are fine-tuned until a microbiome is achieved that is suited for local environmental conditions [17-19]. Thus, while parental and planulation environments were found to influence initial establishment, the host continues to play an active role in shaping the microbiome throughout life history.

In conclusion, the results presented here suggest the $P$. damicornis microbiome is driven by both parental and planulation environments. The dominant Symbiodiniaceae types in recruits were the same as in their respective parents, but also harboured additional environmentally acquired background strains. Bacterial communities were primarily influenced by planulation environment, but at least one bacterial strain was likely acquired within the parental environment. Thus, we hypothesize that the establishment of the microbiome in P. damicornis is likely facilitated by mixed mode transmission, but future research is needed for validation.

Acknowledgements The authors would like to thank M. Kebben (AIMS) for assistance with the design of the planulation boxes. Funding was provided by Paul G. Allen Philanthropies, AIMS@JCU, The Explorer's Club and the ARC CoE for Coral Reef Studies, as part of HE's PhD research. HE acknowledges receipt of an AIMS@JCU Postgraduate Scholarship. Sequence data is available on the NCBI Sequence Read Archive under the accession PRJNA492366.

\section{Compliance with ethical standards}

Conflict of interest The authors declare that they have no conflict of interest.

Publisher's note: Springer Nature remains neutral with regard to jurisdictional claims in published maps and institutional affiliations.

\section{References}

1. Bourne DG, Morrow KM, Webster NS. Insights into the coral microbiome: underpinning the health and resilience of reef ecosystems. Annu Rev Microbiol. 2016;70:317-40.

2. Nitschke MR, Davy SK, Ward S. Horizontal transmission of Symbiodinium cells between adult and juvenile corals is aided by benthic sediment. Coral Reefs. 2016;35:335-44.

3. Apprill A, Marlow HQ, Martindale MQ, Rappé MS. Specificity of associations between bacteria and the coral Pocillopora meandrina during early development. Appl Environ Microbiol. 2012;78:7467-75.

4. LaJeunesse TC, Thornhill DJ, Cox EF, Stanton FG, Fitt WK, Schmidt GW. High diversity and host specificity observed among symbiotic dinoflagellates in reef coral communities from Hawaii. Coral Reefs. 2004;23:596-603. 
5. Leite DCA, Leão P, Garrido AG, Lins U, Santos HF, Pires DO, et al. Broadcast spawning coral Mussismilia Hispida can vertically transfer its associated bacterial core. Front Microbiol. 2017;8:112.

6. Quigley KM, Warner PA, Bay LK, Willis BL. Unexpected mixed-mode transmission and moderate genetic regulation of Symbiodinium communities in a brooding coral. Heredity. 2018;121:524-36.

7. Lesser MP, Stat M, Gates RD. The endosymbiotic dinoflagellates (Symbiodinium sp.) of corals are parasites and mutualists. Coral Reefs. 2013;32:603-11.

8. Sharp KH, Ritchie KB, Schupp PJ, Ritson-Williams R, Paul VJ. Bacterial acquisition in juveniles of several broadcast spawning coral species. PLOS ONE 2010;5:1-6.

9. Zhou G, Cai L, Yuan T, Tian R, Tong H, Zhang W, et al. Microbiome dynamics in early life stages of the scleractinian coral Acropora gemmifera in response to elevated $p \mathrm{CO} 2$. Environ Microbiol. 2017;19:3342-52.

10. Sharp KH, Distel D, Paul VJ. Diversity and dynamics of bacterial communities in early life stages of the Caribbean coral Porites astreoides. ISME J. 2012;6:790-801.

11. Coenye T, Vandamme P. Diversity and significance of Burkholderia species occupying diverse ecological niches. Environ Microbiol. 2003;5:719-29.

12. Dall'Agnol RF, Plotegher F, Souza RC, Mendes IC, Dos Reis FB, Béna G, et al. Paraburkholderia nodosa is the main N2-fixing species trapped by promiscuous common bean (Phaseolus vulgaris L.) in the Brazilian 'Cerradão'. FEMS Microbiol Ecol. 2016;92:1-14.

13. Santos HF, Carmo FL, Duarte G, Dini-Andreote F, Castro $\mathrm{CB}$, Rosado AS, et al. Climate change affects key nitrogenfixing bacterial populations on coral reefs. ISME J. 2014;8:2272-9.

14. Santos HF, Duarte GAS, Rachid CT, da C, Chaloub RM, Calderon EN, Marangoni LF, de B, et al. Impact of oil spills on coral reefs can be reduced by bioremediation using probiotic microbiota. Sci Rep. 2015;5:18268.

15. Tanner JE. Seasonality and lunar periodicity in the reproduction of Pocilloporid corals. Coral Reefs. 1996;15:59-66.

16. Byler KA, Carmi-Veal M, Fine M, Goulet TL. Multiple symbiont acquisition strategies as an adaptive mechanism in the coral Stylophora pistillata. PLoS ONE 2013;8:1-7.

17. Abrego D, Van Oppen MJH, Willis BL. Onset of algal endosymbiont specificity varies among closely related species of Acropora corals during early ontogeny. Mol Ecol. 2009;18:353243.

18. Nyholm SV, McFall-Ngai MJ. The winnowing: establishing the squid - Vibrio symbiosis. Nat Rev Microbiol. 2004;2:632-42.

19. Lema KA, Willis BL, Bourne DG. Amplicon pyrosequencing reveals spatial and temporal consistency in diazotroph assemblages of the Acropora millepora microbiome. Environ Microbiol. 2014;16:3345-59. 